\title{
Ergotherapie wirkt!
}

- Mit einem ehrgeizigen Motto ging Ende Mai der diesjährige ErgotherapieKongress in Köln an den Start - Ergotherapie zeigt Effekt. Zahlreiche Referenten präsentierten anschaulich den derzeitigen Status quo: Durch die zunehmende Akademisierung entstehen immer mehr Studien, Ergotherapeuten arbeiten an medizinischen Leitlinien und ICF Core Sets mit, Validierungsstudien zu Assessments sind in vollem Gange. Meiner Meinung nach war daher dieses Kongressmotto längst überfällig!

_ Nur an Medizinern und Krankenkassen scheint diese positive Entwicklung vorbeizugehen. Häufig war bei Kollegen Ernüchterung zu spüren, dass sie trotz überdurchnittlichen Engagements von den verordnenden Ärzten nicht wahrgenommen werden. Viele hätten immer noch das antiquierte Bild der Ergotherapeuten als „Langzeittherapeuten“ im Kopf. Das mag früher mancherorts der Fall gewesen sein. Heute aber nutzen wir transparente Assessments zur Befunderhebung und erreichen durch klientenzentrierte und konkrete Zielformulierungen eine zeiteffiziente Therapie.

_ Leider zeigen wir viel zu selten, welche positiven Therapieergebnisse wir dadurch erzielen! Dabei können wir mittlerweile nicht nur mit unserem Erfahrungswissen argumentieren, sondern dieses zusätzlich mit positiven Studienergebnissen belegen. Auf dem Kongress habe ich sie kennengelernt: engagierte Ergotherapeuten, die sich durch Verordnungsrückgänge, finanzielle Einbußen und geringe fachliche Wertschätzung nicht entmutigen lassen. Und die am Transfer von der Theorie in die Praxis mitarbeiten.

_ Die Zeiten, in denen wir uns dafür ausschließlich durch englischsprachige Originalstudien kämpfen mussten, sind vorbei. Nutzen Sie Studienzusammenfassungen, zum Beispiel in ergopraxis oder ergoscience. Diskutieren Sie mit Ihren Kollegen, bilden Sie Netzwerke und Qualitätszirkel. Denn je mehr wir mit einer Stimme sprechen und immer wieder die Wirksamkeit der Ergotherapie betonen, umso wahrscheinlicher ist es, von anderen Akteuren im Gesundheitswesen als professionelle Berufsgruppe wahrgenommen zu werden!

Herzlichst Ihre

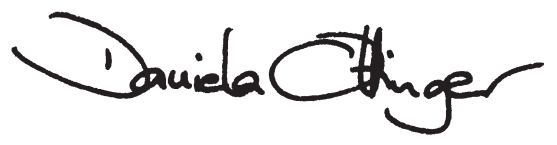

